\title{
Aura-like features and photophobia in sightless migraine patients
}

\author{
Características de fenômenos aura-relacionados e da fotofobia em enxaquecosos \\ deficientes visuais
}

\author{
Greice Cardoso de Carvalho Silva', Cristiana Pessoa de Queiroz Faria Góes ${ }^{2}$, Maurice Borges Vincent ${ }^{2}$
}

\begin{abstract}
Migraine is a central nervous system disorder frequently expressed with paroxysmal visual dysfunctions. Objective: To test the hypothesis that a normal visual input is vital for migrainous aura and photophobia. Methods: We studied the migraine-related visual disturbances in 8 sightless migraineurs identified among 200 visually impaired subjects. Results: The main findings were visual aura and photophobia disappearance along with the development of blindness, abnormal aura [too short, colorful (e.g., blue or fire-like), auditory in nature, or different in shape (round forms)], and the lack of photophobia. Conclusions: We propose that the aura duration should be accepted as shorter in visually impaired subjects. The changes in the aura phenotype observed in our patients may be a result of cerebral plasticity induced by visual impairment and/or the lack of a visual input per se. Integrity of visual pathways plays a key role in migraine visual aura and photophobia.
\end{abstract}

Keywords: migraine with aura, subnormal vision, blindness, visual aura, photophobia

\section{RESUMO}

A enxaqueca é doença neurológica frequentemente associada a anormalidades visuais transitórias. Objetivo: Testar a hipótese de que a visão normal é importante para o fenótipo da aura e da fotofobia. Métodos: Estudamos 8 enxaquecosos deficientes visuais identificados em uma população de 200 indivíduos com visão subnormal. Resultados: Os principais achados foram: o desaparecimento da aura visual e da fotofobia com o início da cegueira; a ocorrência de aura atípica - muito curta, colorida (p. ex. azul, ou cor de fogo) auditiva ou diferente na forma (arredondadas); e a ausência de fotofobia. Conclusões: Propomos que a duração da aura possa ser admitida como mais curta em pessoas com deficiência visual. As mudanças no fenótipo da aura observadas nos nossos pacientes pode ser o resultado da plasticidade cerebral induzida pela deficiência visual e/ou a deficiência visual em si. A integridade da via visual desempenha um papel crucial na aura enxaquecosa e na fotofobia.

Palavras-chave: enxaqueca com aura, visão subnormal, cegueira, aura visual, fotofobia

Migraine is a neurological disorder that frequently involves cortical paroxysmal dysfunction expressed as aura ${ }^{1}$. The most frequent type of aura is visual, sometimes experienced as fortification spectra, known as teichopsia. This typical zigzag, horseshoe-shaped expanding bright perception, usually perceived as complex interlacing lines named "chevaux de frises" by Gowers, followed by a bean-shaped loss of visual acuity, strongly suggests the involvement of visual processing areas. Clinical, experimental, and neuroimaging evidence demonstrates that cortical spreading depression (CSD) is the phenomenon underlying the pathophysiology of bizarre visual perceptions among migraineurs. Computerized models simulating a CSD wave passing through cortical area V1 convincingly reproduce the teichopsia pattern ${ }^{2}$.

The cortical function is deeply dependent on neuronal input. Depriving the cortex of its natural input may influence the cerebral function and change the cortical maps both locally and distantly ${ }^{3}$. In blind individuals, the occipital cortex is critical for tactile Braille reading ${ }^{4}$. The visual cortex is pivotal in the pathophysiology of the migraine aura, the objective of the present study was to investigate whether the phenotype of migraine-related visual phenomena would change in amaurotic patients.

\footnotetext{
${ }^{1}$ Hospital Naval Marcilio Dias, Rio de Janeiro RJ, Brasil;

${ }^{2}$ Faculdade de Medicina, Hospital Universitário Clementino Fraga Filho, Universidade Federal do Rio de Janeiro, Rio de Janeiro RJ, Brasil.

Correspondence: Maurice Vincent; Av. das Américas, 1155 / 504; 22631-000 Rio de Janeiro RJ, Brasil; E-mail: vincent@ufrj.br

Conflict of interest: There is no conflict of interest to declare.

Received 16 December 2013; Received in final form 30 August 2014; Accepted 18 September 2014.
} 


\section{METHODS}

Two hundred visually impaired adult subjects (VIS) were randomly recruited at the Instituto Benjamin Constant (IBC), a Brazilian reference treatment and education center for the unsighted located in Rio de Janeiro. One of the authors (GCCS), a fully trained neurologist, personally interviewed and examined all VIS from October 2010 to May 2011 and from March to July 2012. Study procedures included headache and visual impairment history recording, neurological examination, and review of IBC medical records for access to complete ophthalmological and clinical data. This descriptive, observational study was approved by the Hospital Naval Marcílio Dias (HNMD) ethics committee (56/2010) and authorized by the IBC board on August 10, 2010. All VIS who volunteered to participate signed or fingerprinted an informed consent.

A standardized interview was used to espy migraine patients among VIS. The International Classification of Headache Disorders version II (ICHD-II) ${ }^{5}$ was applied to distinguish migraineurs fulfilling the criteria for the following disorders: migraine without aura, typical aura with migrainous headache, typical aura with nonmigrainous headache, typical aura without headache, probable migraine without aura, and probable migraine with aura, present for at least 1 year prior to the interview. Visual phenomena not necessarily meeting the ICHD-II criteria for a typical aura, either atypical in form, color, and/or duration, as well as occurring without, before, or during the headache (being migrainous or not) were also considered. VIS had to suffer from acquired or congenital amaurosis according to the $10^{\text {th }}$ revision of the International Classification of Diseases (ICD-10) code H54, corresponding to vision impairment categories 3, 4, or 5 (WHO Study Group on the Prevention of Blindness, Geneva, 6-10 November 1972, WHO Technical Report Series No. 518, 1973).

Exclusion criteria comprise ICHD-II familial hemiplegic migraine, sporadic hemiplegic migraine, basilar-type migraine, retinal migraine, migraine complications, chronic migraine, migrainous status, persistent aura without infarction, migrainous infarction, seizure triggered by migraine, probable chronic migraine, migraine onset after the age of 50 years, and comorbidities (systemic or not) potentially causing or manifesting as a migraine-like disorder.

\section{RESULTS}

From the 200 individuals initially interviewed, 9 were excluded: three refused to participate, four because of cognitive impairment, one because of a brain tumor, and one because of marijuana addiction. Among the 191 remaining VIS, 63 fulfilled the criteria for amaurosis. In this subgroup, 35 (55.5\%) reported recurrent headaches, mostly of the migrainous type (23\%-37.0\%), as opposed to 12 (19\%) with other headache disorders and 28 (44\%) headache-free subjects. Eight (12.7\%, 6 females, $40.00 \pm 13.06$ years, range 25-56) migraine with aura patients were selected and studied in further detail (Table 1), of which seven presented with visual aura not necessarily fulfilling Internacional Headache Society (IHS) diagnostic criteria ${ }^{5}$ (in 4 patients, the aura lasted for less than 5 min), and 1 patient reported an auditory aura (uncharacteristic noise). In the majority of our population, the headache started before the visual impairment.

Among the seven amaurotic patients with visual aura, five failed to present an aura following the onset of sightlessness. In patient 1, diagnosed as typical aura with headache not fulfilling migraine criteria, and patient 7 , diagnosed with an atypical auditory aura, the migraine with aura started after the visual impairment. Patient 4 used to perceive scintillations during some headache attacks prior to blindness, changing to perceptions in color and forms after the vision loss. Regardless of the headache type, visual aura symptoms were atypical because of length (too short), colour (blue, silver, or fire-like), and/or shape (round shapes). Photophobia, reported by all patients in whom the headache preceded the blindness in time $(\mathrm{n}=6)$, disappeared after the visual impairment. The remaining 2 subjects denied this symptom.

\section{DISCUSSION}

In this study, we looked for the lifetime prevalence of migraine in a population of visually impaired subjects to address the disease phenotype in this particular population. After blindness, only 1 patient continued to express the aura as before. This suggests that a normal visual input and processing are crucial for aura expression in migraine. Besides, in one patient who became blind years before the migraine attacks, auditory rather than visual phenomena emerged, possibly reflecting an aura-like symptom. Photophobia is clearly dependent on vision because it is not present concomitantly with total blindness.

Kowacs et al. looked for migraine among VIS and found a 6-month prevalence ratio of $14.28 \%$ (compared with $37 \%$ in our material). In their series, 4 subjects had aura: 1 totally blind patient presented an auditory aura and 2 subnormal vision individuals reported an atypical visual aura lasting for 2-4 min. In the last patient aura symptoms disappeared as the vision impairment progressed ${ }^{6}$. Noseda et al. reported about 6 ( 2 with an aura) totally blind and 14 ( 5 with an aura) visually impaired (light perception) migraineurs; however, aura details were not provided?

Aura is supposed to be the clinical counterpart of CSD, a neurophysiological wave of excitation followed by depression of cortical activity ${ }^{8}$. Migraine has been related with cortical hyperexcitability ${ }^{9}$, and the migrainous occipital cortex is 


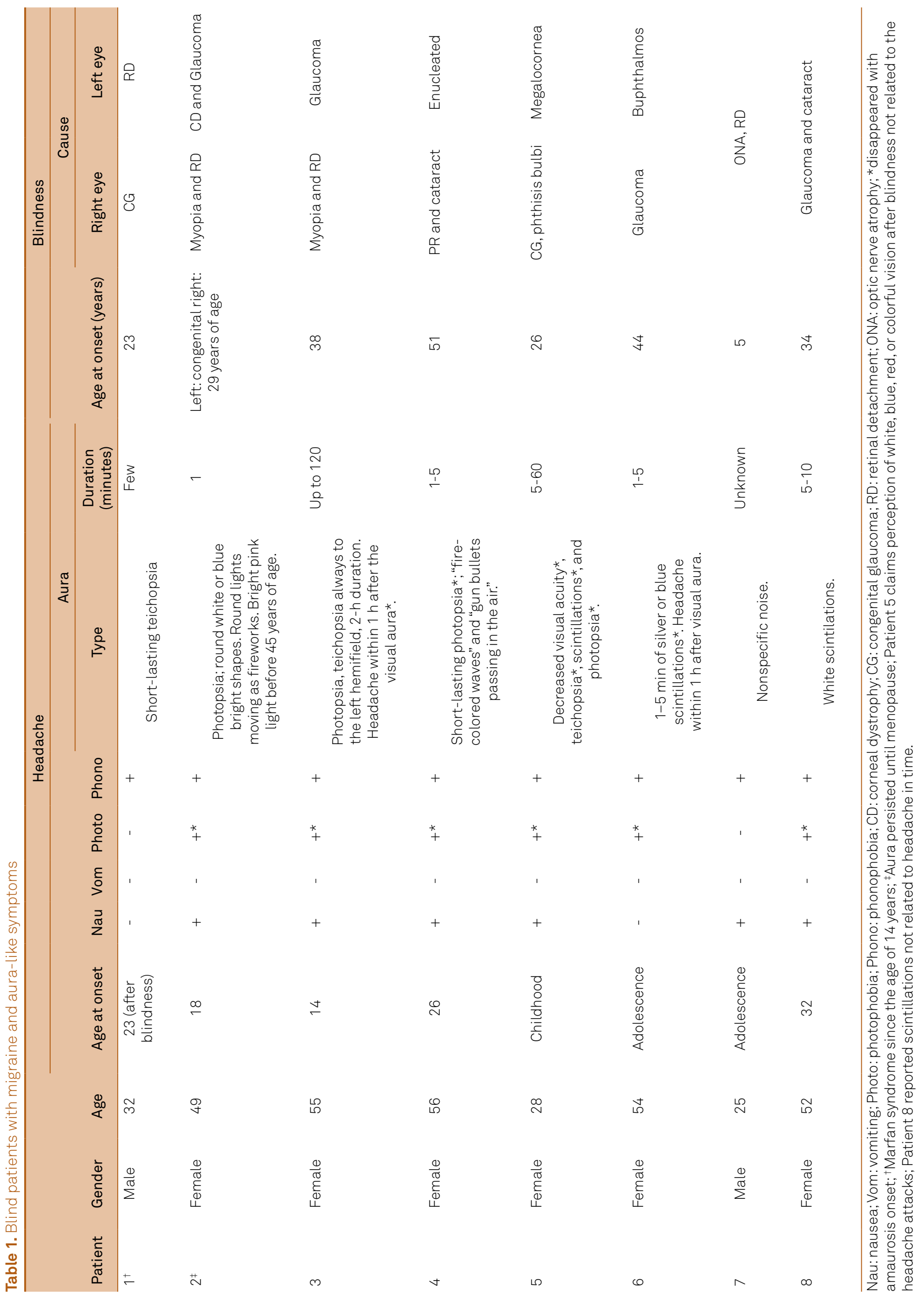


particularly responsive to interictal visual stimulation ${ }^{10}$. There are limited data on CSD provoked by stimuli either than seizure induction or direct chemical/mechanical stimulation; but it is well known that migraine attacks may be triggered by visual stimuli such as sunlight ${ }^{11}$, red-green flickering ${ }^{12}$, or particular striped patterns ${ }^{13}$. Exercise was used to induce a migraine aura during which a CSD-like wave was detected in the brain ${ }^{14}$. In rats, darkness seems to reduce the CSD propagation $^{15}$. Sound may trigger CSD in rats $^{16}$, and light has also been reported to precipitate CSD in rabbits hyperexcited by subconvulsive doses of pentylenetetrazol ${ }^{17}$. Thus, there is clinical and experimental evidence that increased neuronal excitability renders the migrainous cortex more vulnerable to CSD.

Plasticity is an intrinsic endowment of the brain ${ }^{18}$, and blindness induces substantial cerebral reorganization ${ }^{19}$. Blind individuals may compensate for the lack of sight by developing hypereffective nonvisual senses. Although tactile input activates the visual cortex in sighted individuals ${ }^{20}$, blinds activate their primary visual areas V1 and V2 during Braille reading as a compensatory cross-modal strategy. ${ }^{4}$ Blind subjects develop auditory abilities beyond controls ${ }^{21}$, and the absolute pitch is more prevalent in blind musicians ${ }^{22}$. Sightless people detect much more efficiently moving sounds ${ }^{23}$.

Therefore, in theory, noncortical blindness should not preclude CSD from occurring in a migraineous brain because the cortex remains functional and is activated by various inputs. Since the occipital cortex may change from processing visual information to processing other sensory modalities in sightlessness, we hypothesized that the lack of visual input would render the visual cortex less susceptible to CSD, leading to the cessation of the visual auras. Likewise, as sight deteriorates before blindness, subnormal vision would partially reduce CSD susceptibility, possibly explaining the atypical visual auras, mostly too short or expressing color changes not commonly observed in ordinary migraine. Alternatively, the cortical reorganization induced by the lack of vision could still allow CSD but change just its clinical expression, leading to the discontinuation of visual phenomena. If this hypothesis is correct, the auditory aura referred by patient 7 could be the result of an aberrant activation as a result of blindness.

It is noteworthy that visual phenomena were significantly shorter in many VIS. According to ICHD-II, an aura should develop gradually over 5-20 min and last for less than $60 \mathrm{~min}$. Each aura symptom lasts, by definition, $\geq 5$ and $\leq 60$ $\min ^{5}$. These time restrictions are maintained in the present ICHD-3 beta version ${ }^{24}$. In half of our cases, the visual symptoms possibly reflecting aura were shorter than $5 \mathrm{~min}$. Based on these results, we suggest that the aura limit of 5-60 min should not encompass VIS. More subnormal vision subjects must be studied to confirm this finding. The reason as why aura is shorter among VIS remains unknown; however, it may be the result of cortical plasticity and/or a lack of visual input to the visual cortex.
Auditory aura is rarely observed in migraine, but auditory hallucination has been reported as a type of acoustic aura $^{25}$. Our case and the one described by Kowacs et al. ${ }^{6}$ in a small sightless population contrast the rarity of this phenomenon in ordinary migraine, indicating that acoustic aura may be significantly more common among blind subjects. Speculatively, if the lack of vision result in the overactivation of cortical areas related to hearing, this could favor an auditory aura in this population.

Photophobia is present in $>80 \%$ of migraine patients ${ }^{26}$ and seems to be closely inter-related with trigeminal pain. Painful ${ }^{27}$ and optokinetic simuli ${ }^{28}$ increase light discomfort in migraineurs. In controls, luminous stimulation at certain intensities did not lead to the activation of the visual cortex without concomitant pain as detected by positron emission tomography; however, in migraineurs, cortical activation occurred at the same luminous stimulation levels without simultaneous pain, which in turn potentiated the light activation even further ${ }^{29}$.

The pathophysiology of photophobia is largely unknown and may involve non-image formation visual pathways. The fact that mice lacking rods and cones showed normal suppression of pineal melatonin in response to monochromatic light was the first evidence of an additional ocular photoreception in mammals. Melanopsin, an opsin/vitamin A-based photopigment sensitive to blue stimuli present in some retinal ganglion cells ${ }^{30}$, may play a key role in migraine photophobia. In contrast with the present findings, sensitivity to light was reported by blind migraineurs who had preservation of pupillary light response and circadian photoentrainment; however, in patients with bilateral enucleation or damage to the optic nerves, photophobia was absent ${ }^{7}$, indicating that the image formation input is not obligatory for photophobia. As shown in rats, it is possible that retina-originated fibers projecting to the thalamus induce retinal photoactivation in a discrete area at the posterior thalamus where dura-sensitive fibers converge ${ }^{7}$. In our cases, no blind patient admitted pain exacerbation or discomfort by light. This is probably because of the fact that rods, cones, and melanopsin perceptions were all damaged in our cases.

The small number of subjects and the lack of congenitally blind subjects are the limitations of the present study. We are completely aware that memory biases could have somehow interfered with our results. Reviewing the medical records was a possible way to minimize this drawback. However, we are confident that the cases reported here in suggest that visual function is crucial for the expression of a migraine aura and photophobia, regardless of the visual cortex integrity.

\section{Acknowledgments}

We are indebted to Instituto Benjamin Constant for their cooperation with this study. 
1. Pietrobon D, Moskowitz MA. Pathophysiology of migraine. Annu Rev Physiol. 2013;75(1):365-91. http://dx.doi.org/10.1146/annurevphysiol-030212-183717

2. Dahlem MA, Engelmann R, Lowel S, Muller SC. Does the migraine aura reflect cortical organization? Eur J Neurosci. 2000;12(2):767-70. http://dx.doi.org/10.1046/j.1460-9568.2000.00995.x

3. Kujala T, Alho K, Naatanen R. Cross-modal reorganization of human cortical functions. Trends Neurosci. 2000;23(3):115-20.

4. Hamilton RH, Pascual-Leone A. Cortical plasticity associated with Braille learning. Trends Cogn Sci. 1998;2:168-74. http://dx.doi. org/10.1016/s0166-2236(99)01504-0

5. Headache Classification Subcommittee of the International Headache Society. The International Classification of Headache Disorders: 2nd ed. Cephalalgia. 2004;24(Suppl 1):S9-160.

6. Kowacs PA, Piovesan EJ, Lange MC, Weneck LC, Tatsio CE, Ribas LC etal. Prevalence and clinical features of migraine in a population of visually impaired subjects in Curitiba, Brazil. Cephalalgia. 2001;21(9):900-5. http://dx.doi.org/10.1046/j.1468-2982.2001.00286.x

7. Noseda R, Kainz V, Jakubowski M, Gooley JJ, Saper CB, Digre K et al. A neural mechanism for exacerbation of headache by light. Nat Neurosci. 2010;13(2):239-45. http://dx.doi.org/10.1038/nn.2475

8. Leão AAP. Spreading depression of activity in cerebral cortex. J Neurophysiol. 1944;7:359-90.

9. Welch KM, D'Andrea G, Tepley N, Barkley G, Ramadan NM. The concept of migraine as a state of central neuronal hyperexcitability. Neurol Clin. 1990;8(4):817-28.

10. Vincent M, Pedra E, Mourao-Miranda J, Bramati IE, Henrique AR, Moll J. Enhanced interictal responsiveness of the migraineous visual cortex to incongruent bar stimulation: a functional MRI visual activation study. Cephalalgia. 2003;23(9):860-8. http://dx.doi. org/10.1046/j.1468-2982.2003.00609.x

11. Bekkelund SI, Hindberg K, Bashari H, Godtliebsen F, Alstadhaug KB. Sun-induced migraine attacks in an Arctic population. Cephalalgia. 2011;31 (9):992-8. http://dx.doi.org/10.1177/0333102411409071

12. Cao Y, Welch KM, Aurora S, Vikingstad EM. Functional MRI-BOLD of visually triggered headache in patients with migraine. Arch Neurol. 1999;56(5):548-54. http://dx.doi.org/10.1001/archneur.56.5.548

13. Harle DE, Shepherd AJ, Evans BJ. Visual stimuli are common triggers of migraine and are associated with pattern glare. Headache. 2006;46(9):1431-40. http://dx.doi.org/10.1111/j.15264610.2006.00585.x

14. Hadjikhani N, Sanchez del Rio M, Wu O, Schwartz D, Bakker D, Fischi $B$ et al. Mechanisms of migraine aura revealed by functional MRI in human visual cortex. Proc Natl Acad Sci U S A. 2001;98(8):4687-92. http://dx.doi.org/10.1073/pnas.071582498

15. Batinga H, Barbosa PP, Ximenes-da-Silva A. Daytime modulation of cortical spreading depression according to blood glucose levels. Neurosci Lett. 2011;491(1):58-62. http://dx.doi.org/10.1016/j. neulet.2011.01.008

16. Vinogradova LV, Kuznetsova GD, Coenen AM. Unilateral cortical spreading depression induced by sound in rats. Brain Res. 2009;1286:201-7. http://dx.doi.org/10.1016/j.brainres.2009.06.047
17. Van Harreveld A, Stamm JS. Cortical responses to metrazol and sensory stimulation in the rabbit. Electroencephalogr Clin Neurophysiol. 1955;7(3):363-70. http://dx.doi.org/10.1016/00134694(55)90005-5

18. Pascual-Leone A, Amedi A, Fregni F, Merabet LB. The plastic human brain cortex. Annu Rev Neurosci. 2005;28:377-401. http://dx.doi. org/10.1146/annurev.neuro.27.070203.144216

19. Collignon O, Dormal G, Albouy G, Vandewall G, Voss P, Phillips C et al. Impact of blindness onset on the functional organization and the connectivity of the occipital cortex. Brain. 2013;136(9):2769-83. http://dx.doi.org/10.1093/brain/awt176

20. Sathian K. Visual cortical activity during tactile perception in the sighted and the visually deprived. Dev Psychobiol. 2005;46(3):279-86. http://dx.doi.org/10.1002/dev.20056

21. Morgan M. Sensory perception: supernormal hearing in the blind? Curr Biol. 1999;9(2):R53-4. http://dx.doi.org/10.1016/S09609822(99)80009-8

22. Hamilton RH, Pascual-Leone A, Schlaug G. Absolute pitch in blind musicians. Neuroreport. 2004;15(5):803-6. http://dx.doi. org/10.1097/00001756-200404090-00012

23. Lewald J. Exceptional ability of blind humans to hear sound motion: implications for the emergence of auditory space. Neuropsychologia. 2013;51(1):181-6. http://dx.doi.org/10.1016/j. neuropsychologia.2012.11.017

24. Headache Classification Committee of the International Headache S. The International Classification of Headache Disorders, 3rd edition (beta version). Cephalalgia. 2013;33(9):629-808. http://dx.doi. org/10.1177/0333102413485658

25. Feltz-Cornelis CM, Biemans H, Timmer J. Hearing voices: does it give your patient a headache? A case of auditory hallucinations as acoustic aura in migraine. Neuropsychiatr Dis Treat. 2012;8:105-11. http://dx.doi.org/10.2147/NDT.S29300

26. Rasmussen BK, Jensen R, Olesen J. A population-based analysis of the diagnostic criteria of the International Headache Society. Cephalalgia. 1991;11(3):129-34. http://dx.doi.org/10.1046/j.14682982.1991.1103129.x

27. Drummond PD, Woodhouse A. Painful stimulation of the forehead increases photophobia in migraine sufferers. Cephalalgia. 1993;13(5):321-4. http://dx.doi.org/10.1046/j.14682982.1993.1305321.x

28. Drummond PD. Motion sickness and migraine: optokinetic stimulation increases scalp tenderness, pain sensitivity in the fingers and photophobia. Cephalalgia. 2002;22(2):117-24. http://dx.doi. org/10.1046/j.1468-2982.2002.00332.x

29. Boulloche N, Denuelle M, Payoux P, Fabre N, Trotter Y, Geraud G. Photophobia in migraine: an interictal PET study of cortical hyperexcitability and its modulation by pain. $J$ Neurol Neurosurg Psychiatr. 2010;81(9):978-84. http://dx.doi.org/10.1136/ jnnp.2009.190223

30. Hankins MW, Peirson SN, Foster RG. Melanopsin: an exciting photopigment. Trends Neurosci. 2008;31(1):27-36. http://dx.doi. org/10.1016/j.tins.2007.11.002 